\title{
Bed of roses? The role of garden space in older people's well-being
}

\section{Elizabeth Burton MA Cantab, DipArch, DipUD, PhD}

Professor of Sustainable Building Design and Well-being, School of Engineering and Warwick Medical School (joint appointment), University of Warwick, Coventry, UK

Lynne Mitchell BA(Hons), MPhil, PhD

Senior Research Fellow, School of Engineering and Warwick Medical

School (joint appointment), University of Warwick, Coventry, UK
Chris Stride PhD, C.Stat

Senior Lecturer/Statistician, Institute of Work Psychology, University of Sheffield, Sheffield, UK

The purpose of this research was to investigate the role of outdoor housing environment (OHE), including front and back gardens, yards, courtyards, patios and balconies, in older people's well-being. Descriptions of their OHEs were collected from 2558 individuals living in $\mathbf{5 2 6}$ distinct housing developments using a postal questionnaire. A large range of background variables were measured, mainly through the questionnaire. Characteristics of respondents' immediate neighbourhood environments were measured from digital maps and satellite/bird's-eye images. Among the OHE variables, statistically significant predictors of well-being were having one's own patio (as opposed to shared or none), and having a green view from one's living area (a positive effect on well-being). The authors conclude that it would be beneficial for older people's housing to include private patio space, where possible, as well as a large amount of greenery. The research supports the claim that older people benefit from green space as much by viewing it from inside as spending time in it. If older people have no or very little garden space, a green street environment is likely to increase their well-being, especially if it can be seen from their home.

\section{Introduction}

In health research, increasing attention is being paid to the built environment (Jackson, 2003; Northridge et al., 2003; Srinivasan et al., 2003; Thomson et al., 2009). Of particular relevance is its role in addressing the challenges of an ageing society (Burton et al., 2011), a worldwide phenomenon. To reduce the burden of care, policies now centre on facilitating independence in older age or allowing people to 'age in place'. Over the last few decades, new forms of housing have been developed to address the needs of older people, from sheltered housing in the $\mathrm{UK}$, to assisted living and retirement villages in the USA, and cohousing in Scandinavia. However, the design of such housing is rarely based on evidence; guidance tends to stem from assumptions or professional opinions about what older people want and what is best for them.

In terms of desired outcomes, the focus has shifted from extending life to extending 'quality life'. This matches growing interest in 'positive mental health', a term that is often used interchangeably with 'mental well-being', as a valid health objective (Gale et al., 2011; Stewart-Brown et al., 2009). There is ongoing debate about the definition of mental well-being, but generally there is agreement that it is a 'state of health, happiness and prospering, comprising two dimensions, namely how we feel and how we function' (Bond et al., 2012: p. 2). There is evidence to suggest that mental well-being has major implications not only for health but also for longevity and economic productivity (Veenhoven, 2010).

Studies have indicated that mental well-being in later life is influenced by the built environment, which is an important mediator of ageing experiences and opportunities (Liu et al., 2009). As Prieto-Flores et al. (2011: p. 1183) point out, "the relationship of the residential environment with health and well-being has received special attention in aging research'. Most research to date has been on either the internal environment of the home (Howden-Chapman et al., 2007) or the wider neighbourhood environment (e.g. Gilroy, 2008; WHO, 2007). Few studies have investigated the more immediate outdoor environment - that is the garden space around homes. This is the focus of this research. The outdoor housing environment (OHE) or 'garden space' - these two terms will be used interchangeably - is often but not always green. It can be private or shared with other residents and can include front gardens, back gardens, balconies, terraces, patios and courtyards. Older people's inability to look after their 


\section{Offprint provided courtesy of www.icevirtuallibrary.com Author copy for personal use, not for distribution}

garden is sometimes cited as a reason for moving into retirement housing, where gardens are communal and tended by staff. However, because older people tend to spend more time at home, it could be argued that the OHE is particularly important to them. Previous research suggests that garden space can positively impact older people's well-being, both mental and physical.

The OHE may boost mental health in multiple ways. First, it can provide an attractive, visually appealing setting for housing, and the opportunity to express personal tastes and preferences (White et al., 2013). This setting also offers pleasant views from inside the home, leading to greater satisfaction with life. Second, garden space can provide opportunities for socialising. Neighbours can chat over the garden fence and friends can be invited round for barbeques. Third, it can encourage attention restoration, recovery from mental fatigue (Grahn and Stigsdotter, 2010) and, particularly where there are natural features such as trees, shrubs, flowers and water, stress mitigation. The latter may operate by way of the mechanism of biophilia, the theory that there is an instinctive bond between human beings and other living systems (Wilson, 1984; see, e.g. Beil and Hanes, 2013; Beukeboom et al., 2012; Lottrup et al., 2013; van den Berg et al., 2010; Ward Thompson et al., 2012), or through reduction in noise annoyance (e.g. trees and greenery absorb sound from traffic) (Li et al., 2012).

Researchers are acknowledging that such mental benefits of green space (including gardens) may not be limited to time spent in them. It may be that the strongest impacts of greenery derive from viewing it from inside the home or workplace. Roger Ulrich's work demonstrates the benefits of viewing nature through windows to the outside (e.g. Ulrich et al., 1991). His focus has been the setting of healthcare facilities, but others have extended this to the home environment (Kaplan, 2001; Velarde et al., 2007). Kuo and Sullivan (2001), for example, took advantage of a naturally occurring experiment to investigate the impact of residential greenery for urban public housing residents. Residents living in greener housing blocks reported less aggression and violence than their counterparts in more barren blocks.

The OHE can also benefit physical health, through providing space and incentives for physical activity, particularly in the form of gardening, which is a valuable exercise for older people (Mytton et al., 2012). There are countless health benefits stemming from physical activity, and spending time in the OHE can be beneficial in terms of giving access to fresh air and sunlight (vitamin D).

The OHE has the potential to play an important role in the lives of older people (de Vries et al., 2003; Gilroy et al., 2004).
Yet, some new housing developments aimed specifically at older people are being built without any such space. Without an accumulation of evidence for its benefits, it is difficult to make the argument that the OHE matters. Further, there is a clear need for knowledge on how best to design garden space in housing for older people, particularly where high densities are required. New types of outdoor space are being created around and within the new models of housing for older people. Generally, this space is communal, but there are questions about whether or not this provides the same benefits to older people as personal space. The aim of this study was to investigate the role of the OHE in older people's well-being, in order to contribute towards evidence-based design. The specific research propositions are

- having garden space enhances the mental well-being of older people, although this effect may vary according to the type of space provided (balconies, patios, terraces, courtyards etc.)

- the benefits of garden space are greatest where this space is for personal use only

- having a green view from inside the home enhances mental well-being

- the positive effect of greenness of garden space on wellbeing is greatest for older people as they tend to spend more time at home (younger people have interaction with natural elements in their work or wider neighbourhood/ town environment).

\section{Methodology}

\subsection{Overall approach}

There are many challenges in conducting research on the built environment and well-being, such as the impracticality of carrying out randomised trials or controlled experiments, the need to account for residential self-selection or drift, difficulties in controlling for confounding influences on well-being and the lack of objective built environment measures, especially those that can be obtained on a large scale (Mair et al., 2008; Yen et al., 2009). Such difficulties and the resulting paucity of research to date has led to a dearth of practical applications - that is there is little knowledge of how the built environment should be changed or designed differently to optimise well-being (Dunton et al., 2009). It has been difficult to generate specific design guidance when the built environment has been treated as a unitary construct rather than the product of many different elements. Similarly, several studies have used subjective ratings of environmental quality by residents or researchers as opposed to objective descriptions of specific features, or have focused on aspects of the environment over which designers and developers have little control (Duarte et al., 2010; Dunstan et al., 2005; Galea et al., 2005). 


\section{Offprint provided courtesy of www.icevirtuallibrary.com Author copy for personal use, not for distribution}

Therefore, there were three key principles behind the methodology for this research.

First, because a longitudinal study was impractical within the project deadlines, the authors attempted to optimise their cross-sectional design by sampling a large number of potential respondents from a range of regions, settlement and housing types, eras and densities. Second, factual data were collected from residents on the individual features of their OHE rather than their subjective assessment of it as a whole, to minimise measurement error. Third, given the many different, potentially confounding influences on well-being, the authors aimed to control for as many of these as possible, both personal and situational. For example, large, green gardens are often found in leafy, suburban areas with many open green spaces and parks. The authors wanted to be sure that any effect of garden space was due to the space itself rather than just the result of living in a generally green neighbourhood. Likewise, dwellings built in different eras tend to have different types of garden space due to the constraints of space, changing design fashions and planning regulations. Therefore, we controlled for construction era in order to identify effects above and beyond living in housing of a certain type.

\subsection{Sample selection and data collection}

The research reported here is one strand of a larger project funded by the Engineering and Physcial Sciences Research Council (Inclusive Design for Getting Outdoors, or I'DGO, see www.idgo.ac.uk). The aim of I'DGO was to investigate the implications of urban intensification policies for older people, in particular in terms of higher-density living. Therefore, it was essential to identify a sample of older people living in a wide range of types of housing, including examples built before and after the urban intensification policies had been established around the start of the twenty-first century. A stratified sampling technique was used, with sampling taking place at the development level. A development is defined as a group of dwellings built together (at the same time), by the same developer or developers. The authors selected developments across Great Britain to provide a balanced mix within the following categories

- tenure - private, social and mixed tenure housing

region - seven regions: Scotland, Wales and five in England

- settlement types - city, town, village and rural

- era - from pre-Victorian to urban renaissance (post-2000)

- housing type - terrace (or 'row'), semi-detached and detached houses or bungalows and apartment blocks

- density - from low to high

age- and non-age-specific housing (i.e. housing built specifically for older people and housing for the general population).
With respect to age, the survey sample was not designed to be representative of the UK population as a whole. The intention was that it would be representative of the older population living in a wide range of differing residential settings.

Several strategies were used to identify possible developments. Housing associations (e.g. Peabody Trust and Places for People) were approached to join the I'DGO advisory group. They then provided information about their residential developments. Recent (post-2000) developments were identified from the Commission for Architecture and the Built Environment website, www.cabe.org.uk (archived 18 January 2011). For each development considered for inclusion, the location, number of residents, approximate area, population density, layout and any special features were recorded. To capture people living in 'ordinary' individual homes as well as particular types of development, an area around each development was also sampled. Non-age-specific social housing was identified in the surrounding area using information from district, borough, city and town councils and urban regeneration websites.

A total of 545 distinct developments, containing 15498 distinct dwellings were sampled. The main method of data collection was a questionnaire, administered through a postal survey. The postal method was used because it is the least intrusive method, and allowed data to be gathered from a large sample across the whole of Great Britain. Reminder letters were sent out to optimise response rates. The questionnaire comprised four parts

- questions about participants' garden space, including what they currently have access to, whether shared with others or to themselves

- questions about views to the outside from inside their home

- questions about their general well-being

- questions about background personal and household information.

In developments of up to 60 dwellings, a questionnaire was sent to each dwelling, but for larger developments systematic sampling of every second or third dwelling was used, to generate a sample of approximately 60 dwellings.

Questionnaire data from householders were supplemented by the collection of objective data on various background variables at the development level, measured from images of each development accessed by way of remote digital sources (EDINA Digimap Carto, Google Earth and Microsoft Bing Bird's Eye), a method that has been found to be effective in previous research (Clarke et al., 2010). 


\section{Offprint provided courtesy of www.icevirtuallibrary.com Author copy for personal use, not for distribution}

\subsection{Questionnaire measures}

\subsubsection{Measures of well-being}

There are a small number of standardised measures of mental well-being or positive mental health frequently used in medical research, but each is composed of a large number of items, rendering them too time consuming given both the scope of this study, and the demographic group on which the study was focused. Therefore, the authors identified four simple single items to measure the mental well-being facets that are considered most likely to be impacted by the OHE - that is, quality of life, enjoyment of life, general health status and extent of independence - and that would collectively encapsulate the respondent's overall mental well-being. The specific wording of these items was

- 'Thinking about your life as a whole, how would you rate your quality of life?' (response coding: 4 'very good', 3 'good', 2 'fair', 1 'poor')

- 'To what extent would you agree that you enjoy life?' (response coding: 5 'strongly agree', 4 'agree', 3 'neither agree nor disagree', 2 'disagree', 1 'strongly disagree')

- 'How is your health in general?' (response coding: 6 'excellent', 5 'very good', 4 'good', 3 'fair', 2 'poor', 1 'very poor')

— 'Thinking about your life, how independent do you feel?' (response coding: 4 'very independent', 3 'fairly independent', 2 'not very independent', 1 'not at all independent').

The authors assessed the validity and reliability of this potential scale of items using exploratory factor analysis and reliability analysis (Tabachnick and Fidell, 2007). The items were found to share large positive correlations (Pearson's $r>0 \cdot 4$ ), each load strongly on to the single underlying factor extracted, and together exhibit adequate internal consistency (Cronbach's alpha $=0 \cdot 78$ ). As such, they were suitable for incorporation into a single composite score measuring the construct of well-being for each respondent, achieved by calculating the unweighted mean across them.

\subsubsection{Measures of characteristics of the OHE}

Information on the presence or absence of six specific types of garden space within a respondent's dwelling - front garden; back garden; patio, terrace or veranda; yard or equivalent paved area; balcony; and courtyard - was obtained through the questionnaire. Respondents were simultaneously asked about their degree of personal access to each space. These measures were designed to be as objective as possible (i.e. to reflect actual features of a respondent's garden space rather than subjective opinions of them). For each type of space, the respondent was simply asked to select whether it was 'present' or 'not present', and whether it was 'for shared/communal use', or whether it was present for their 'own use'. Further, a single item assessed their perception of the collective greenness of this garden space to which they had access, which they were asked to rate as: 4 'very green', 3 'fairly green', 2 'not very green', 1 'not at all green'.

In addition to garden space, respondents were also asked about the view from their dwelling, specifically the extent to which they considered it green (again coded as 4 'very green', 3 'fairly green', 2 'not very green', 1 'not at all green'), the number of trees that they could see and their assessment of the view's character (they were asked to select any of the following types which they believed the character of their view to be 'best described by' 'garden (yours and/or neighbours)'; 'countryside'; 'street'; 'woodland/other wild space'; 'park/other maintained green space'; 'neighbouring buildings'; 'off-street parking or garages'; 'outdoor space for waste bins'; 'other').

\subsubsection{Background measures}

Background and demographic measures that might potentially confound the relationship between OHE and mental wellbeing were collected, in order to control for them in the analysis. These were identified from the literature as characteristics likely to influence aspects of well-being, and that might also be related to the physical built environment that a household would be experiencing. Specifically they comprised (from the questionnaire) age, gender, limiting disability, ethnic origin, household size, children in household and regularly visiting, form of dwelling (detached, semi-detached etc., and lowest floor), economic status, and length of residence in dwelling. Some of the development-level background measures were sourced as a part of the sample selection process: region, location type, development age, ownership type and age specificity. Others were collected using the satellite imagery, specifically the size of residential location the development fell within (city/large town, small/medium town, large village/ small town, small village); the era of the development $(2000+$ (post-urban intensification policy); 1980-1999 (post-modern); 1960-1979 (modern); 1946-1959 (post-World War II); 19191945 (inter-war and World War II); 1901-1918 (Edwardian and World War I); 1837-1900 (Victorian); or pre-1837 (preVictorian)), proximity (measured as a walkable route, not a radius) to local facilities such as shops (within $300 \mathrm{~m}$, further than $300 \mathrm{~m}$, further than $300 \mathrm{~m}$ and site on settlement edge) and public open space (within $300 \mathrm{~m}$, by type as park/playground; recreation ground/playing field; public square, plaza or village green; nature reserve, countryside or common; river or canal towpath; beach or coastline; no public open space except roads). In addition, the maximum number of storeys across buildings in the development (and hence their capability to both block and enhance views, limit social interaction and isolate residents in other ways) was recorded. 


\section{Gender}

Age of respondent: years

Ethnic origin

Disability that limits

Accommodation type

Lowest floor level of household

Tenure in current household: years

Resident adults

Resident children

Residents in paid employment

\author{
Male $=33 \cdot 3 \%$, female $=66 \cdot 7 \%$ \\ Mean $=62 \cdot 2$, median $=65 \cdot 0, \mathrm{SD}=19 \cdot 5$ \\ White $=91 \cdot 6 \%$, non-white $=8.4 \%$ \\ No $=67.6 \%$, yes $=32.4 \%$ \\ Detached house or bungalow $=8.1 \%$ \\ Semi-detached house or bungalow $=10 \cdot 3 \%$ \\ Terraced house or bungalow $=14.7 \%$ \\ End of terrace house or bungalow $=5 \cdot 2 \%$ \\ Flat, maisonette or tenement $=56 \cdot 1 \%$ \\ Other accommodation type $=5 \cdot 6 \%$ \\ Basement $=2 \cdot 6 \%$, ground floor $=64 \cdot 2 \%$, \\ First floor $=18.4 \%$, second floor or higher $=14.8 \%$ \\ Mean $=7 \cdot 8$, median $=4 \cdot 8, \mathrm{SD}=8.9$ \\ $1=57.4 \%, 2=37.0 \%, 3+=5.6 \%$ \\ $0=82 \cdot 4 \%, 1=7 \cdot 4 \%, 2=7 \cdot 4 \%, 3+=2 \cdot 8 \%$ \\ $0=63 \cdot 7 \%, 1=19 \cdot 9 \%, 2+=16 \cdot 4 \%$
}

Table 1. Summary of background information for response sample of households $(N=2558)$

\subsection{Sample description: response rates and demographic characteristics}

In all, 2558 completed questionnaires were received, from within 526 distinct developments, giving a response rate of $16.5 \%$ among the respondents surveyed. This is relatively poor, reflecting the focus on older ages and over-sampling of socially rented properties. On review, there were no obvious discrepancies in the demographic characteristics of respondents and non-respondents. When assessed by region, response rates varied from $10.8 \%$ in Scotland to $21.0 \%$ in the South West of England; similar variations existed by housing type, with response rates ranging from $15 \cdot 3 \%$ of surveyed households in social age-specific housing to $20 \cdot 3 \%$ in private age-specific housing.

Demographic properties of the response sample at the respondent (i.e. household) level are summarised in Table 1. The age profile of respondents reflects the purposive oversampling from among the older population and, in particular, those living in age-specific accommodation.

\subsection{Sample description: respondents' OHE}

Across the sample, the most frequently reported types of OHE were front garden and back garden, with approximately $60 \%$ of respondents having access to one or both of these on either a personally owned or shared basis. Only $1.7 \%$ of respondents were without access to any type of own or shared garden space. Nearly half $(43 \cdot 2 \%)$ of the respondents described their OHE as 'very green', with a further $40 \cdot 2 \%$ considering it to be 'fairly green'. Similarly, $31 \cdot 2 \%$ of respondents described the view from their living area as 'very green', with a further $40.6 \%$ considering it to be 'fairly green'. Half the sample could see between one and nine trees from their living area, with a further $40 \cdot 7 \%$ able to see ten or more trees.

\subsection{Sample description: background variables}

Summary statistics of the physical environment background variables, collected by desk-based methods, that describe the 526 developments for which the authors had at least one respondent, are given in Table 2.

This again reflects the over-representation of age-specific developments within the sample, the majority of which have been built since the 1960s.

\subsection{Analysis method}

The authors' hypotheses regarding the impact of availability of different types of garden space on well-being were tested using multi-level regression analyses (Field, 2009). This technique was chosen due to the data structure, in which household survey responses are each nested within a specific development, for which development-level background information was collected. Multi-level modelling enables the variance in the outcome of well-being to be divided into within- and between-development parts, and hence the portions of that variance explained by both respondent level and development level constructs to be quantified. By acknowledging the respective sample sizes at each level it also avoids the false sample size inflation for development level variables, and the resultant potential for type I errors when assessing their 


\author{
Age specificity of development \\ Ownership type \\ Era of development
}

Development size: $\mathrm{m}^{2}$

Density (households per $1000 \mathrm{~m}^{2}$ )

Percentage built up

Maximum number of floors

Tree density

Type of surrounding settlement

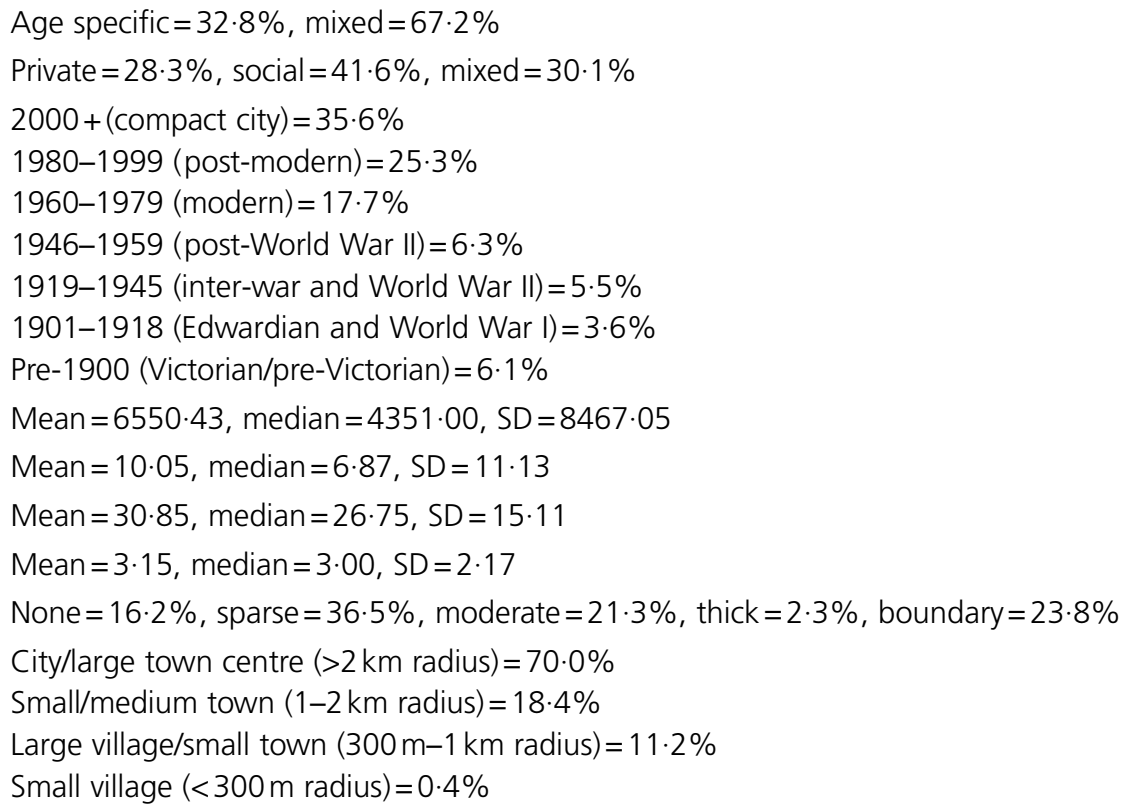

Table 2. Summary of background information for developments ( $N=526$ developments)

effects, which would occur if development level responses were treated as being unique to each subject.

When modelling the impact of OHE on well-being, the authors initially assessed the variance to be explained at the respondent (i.e. household) and development level, and calculated the type I intraclass correlation coefficient statistic (the proportion of variance at each level, commonly abbreviated as ICC(1)). They then first entered both respondent- and development-level background variables that might feasibly confound the relationship, and assessed model fit improvement and variance explained by each set of variables. At the second stage, the authors tested their first two research propositions by entering variables corresponding to the presence or absence of the six specific types of garden space. Specifically, each type of space was represented by two dummy variables, one representing the presence of that type of space as a personal resource (against not having it at all), and the second representing the presence of that type of space as a shared space (against not having it at all). At the third stage, they entered the three variables that collectively measured greenness of $\mathrm{OHE}$ and view from living space. Finally, to test the fourth research proposition, they entered the interaction of respondent's age and greenness of view, to test whether the impact of green views on well-being varied according to a respondent's age.

Given the large samples at both household and development level and the corresponding risks of detecting non-zero yet very small, spurious and practically insignificant effects, the $p<0.005$ level of statistical significance is reported alongside the more commonly employed $p<0 \cdot 05$.

\section{Findings}

Partitioning the variance of well-being produced a residual (within-development) variance of 0.517 , and betweendevelopment intercept variance of 0.078 , giving an ICC(1) statistic of $0 \cdot 131$ - that is, $13 \cdot 1 \%$ of the variance in well-being was attributable to between-development differences.

Adding the potentially confounding household- and development-level 'control' variables significantly improved the model fit. The change in the model deviance was statistically significant (change in deviance $=354$, change in $\mathrm{df}=47$, $p<0.005$ ), and these variables together explained $10 \%$ of the within-development variance (i.e. differences between households in the same development), and more than $95 \%$ of the between-development variance. The statistically significant control variables were ownership status of the property (those renting from council or housing association reported significantly lower well-being), disability (disabled respondents reported significantly lower well-being) and age (older respondents reported significantly lower well-being).

Testing the authors' first and second propositions by adding the six variables representing the presence and extent of personal ownership of different OHE space types also significantly improved the model fit (change in deviance $=27$, change in $\mathrm{df}=12, p<0 \cdot 005$ ), and explained a small but non-trivial 


\begin{tabular}{lccr} 
Predictor & B-coefficient & $95 \%$ Cl for B-coefficient & t-statistic \\
\hline Personal front garden (against ref cat: no front garden) & 0.009 & $(-0.098,0.116)$ & 0.170 \\
Shared front garden (against ref cat: no front garden) & -0.008 & $(-0.102,0.085)$ & -0.177 \\
Personal back garden (against ref cat: no back garden) & 0.103 & $(-0.024,0.230)$ & 1.586 \\
Shared back garden (against ref cat: no back garden) & 0.046 & $(-0.051,0.142)$ & 0.933 \\
Personal patio (against ref cat: no patio) & $0.125^{\star *}$ & $(0.036,0.215)$ & 2.740 \\
Shared patio (against ref cat: no patio) & -0.059 & $(-0.171,0.052)$ & -1.045 \\
Personal yard (against ref cat: no yard) & $-0.155^{* *}$ & $(-0.281,-0.030)$ & -2.430 \\
Shared yard (against ref cat: no yard) & -0.021 & $(-0.128,0.085)$ & -0.391 \\
Personal balcony (against ref cat: no balcony) & 0.021 & $(-0.096,0.139)$ & 0.353 \\
Shared balcony (against ref cat: no balcony) & 0.149 & $(-0.048,0.347)$ & 1.487 \\
Personal courtyard (against ref cat: no courtyard) & 0.056 & $(-0.182,0.295)$ & 0.465 \\
Shared courtyard (against ref cat: no courtyard) & 0.028 & $(-0.082,0.138)$ & 0.501 \\
Extent to which your outdoor space is green & $0.054^{*}$ & $(0.001,0.107)$ & 2.017 \\
Extent to which your view from living area is green & $0.115^{* *}$ & $(0.065,0.165)$ & 4.534 \\
Number of trees from living area in view & 0.035 & $(-0.018,0.087)$ & 1.293 \\
Extent to which your outdoor space is green $\times$ respondent's age & $0.057^{*}$ & $(0.015,0.100)$ & 2.683 \\
\hline
\end{tabular}

${ }^{*} p<0.05,{ }^{* *} p<0.005$

Table 3. Unstandardised estimates of fixed effects of different types of garden space, greenness of garden space, greenness of view and number of trees in view on well-being, having controlled for background physical and demographic variables

portion of the variability in well-being between households (unexplained within-development variance reduced from 0.468 to $0 \cdot 456$, equating to a further $2 \cdot 3 \%$ of the original $0 \cdot 517$ to be explained). Of the six types of OHE space, both back gardens and patios were significantly beneficial to well-being. Personal and shared back gardens were equally beneficial, but a patio only offered significant benefits when it was the respondent's own. These results offer support for their first research proposition, and partial support for their second. Presence of a personal yard was also a significant predictor, although this had a negative effect on well-being.

The authors then added variables corresponding to green view, number of trees visible and overall greenness of the OHE. The change in the model deviance was statistically significant (change in deviance $=52$, change in $\mathrm{df}=3, p<0.005$ ), and these variables together explained a further $3 \%$ of the withindevelopment variance, but less than $1 \%$ of the betweendevelopment variance (although it should be noted that among the development-level control variables was greenness of area). Of the three greenness variables, only greenness of view was statistically significant at the $p<0.005$ level, and had a positive effect on well-being. These results offer support for their third research proposition. Adding these variables to the model removed the significant positive effect of having a back garden.
Finally, the interaction effects were added between age and each of three greenness variables in turn. Only the interaction of age with overall greenness offered a significant (if small) improvement in model fit (change in deviance of 7 on $1 \mathrm{df}$, $p<0 \cdot 005$ ), explaining $<1 \%$ of the variance. The positive effect of overall greenness on well-being is enhanced for older respondents.

Unstandardised regression coefficients (B), $t$-statistics for testing the difference of the respective effect from 0 and $95 \%$ confidence intervals for each effect in this final model are given in Table 3. Effects and confidence intervals for control variables are excluded for parsimony.

\section{Discussion}

The findings show that garden space does matter for older people's well-being. However, looking in more detail, it appears that this effect is attributable mainly to having a patio, and, to a lesser extent, having a back garden. The impact of having a back garden is understandable. This is a space, away from the street, that offers a degree of privacy. It is interesting that both shared and personal back gardens are beneficial for well-being. This suggests that they may play an important role in social interaction - a space to meet people and chat. In the case of back gardens for personal use, only social interaction is 


\section{Offprint provided courtesy of www.icevirtuallibrary.com Author copy for personal use, not for distribution}

likely to stem from 'chatting over the garden fence' or from inviting people round to sit or eat in the space. In shared back gardens, residents are likely to 'bump into' their neighbours or they may sit together if seating is provided.

It was more surprising to discover that patios play a role in older people's well-being. The authors can only speculate about why this might be. Perhaps it is because this space constitutes the most 'useable' space within a garden - it is where people can sit in the sun and where they can eat out and socialise (it is easier to set up chairs and tables on a 'hard' surface). It is also usually a space where people can express their personalities and tastes through pots and other decorative garden accessories. This may be why only personal use patios are beneficial for well-being. Patios are also usually low-maintenance spaces they do not represent a high burden in terms of upkeep. Having a yard has a negative impact on well-being. This may reflect something about the type of housing that includes yards or it may be that yards tend not to be green and natural. Patios are hard landscaped, too, but they tend to butt against a more natural landscape of the back garden - usually lawn.

The findings confirm that the benefits of garden space are greatest where this space is for personal use only, but, in the case of back gardens, shared space also increases well-being. This is good news for retirement housing and new models of older people's housing. Garden space does not have to be for personal use only to be beneficial. It is possible in most developments to include at least some patio space for personal use, certainly for ground floor dwellings. Balconies do not appear to provide the same benefits for dwellings above ground level. It is better to provide some patio space where possible, even if this is not outside a resident's living space.

In line with the research of Ulrich, Kaplan and others, the findings strongly support the claim that green space has a great impact on well-being. The authors found that, for older people in particular, it is the view of greenness that the garden space or other space surrounding the dwelling can provide from inside the home that is important for well-being. The theory of biophilia states that we have an innate desire to have contact with nature. This could explain why a green view affects wellbeing. Older people may be too frail to get out and about regularly. They may spend most of the time indoors. Therefore, their contact with nature is mostly through looking at it from inside. Younger people may be able to compensate for a lack of nature in their home environment by travelling further afield to parks and other green spaces, or their work environments may have a bigger impact on them as they spend most of the day there.

For older people, the view from the living room may not be of garden space. It may be a view of the street. As long as the general outdoor environment - public as well as private space - is green, this will be beneficial for older people. It is important therefore that greenery in public space is maximised through street trees and grass verges.

\section{Conclusions}

The authors believe this is the first quantitative study to investigate the role of garden space in older people's well-being. It is innovative in several ways - that is it considers the concept of well-being within the physical reality of the built environment, and in doing so is genuinely trans-disciplinary; and it develops and uses measures of individual features of the garden environment. The rigour of the research was optimised by use of a large sample, collection of objective measures of the built environment and comparisons between as well as within different age groups. Identifying features of garden space that are positively related to well-being make it possible to apply the findings in future design of housing for older people.

The research suggests that, to optimise well-being in housing for older people, designers and developers should incorporate back gardens (shared or private) and try to provide small private patio areas for as many residents as possible (even those living above the ground floor). Residents benefit from having some small, low-maintenance space they can personalise and call their own. Back gardens should be designed to encourage social interaction, with seating areas and low-to-medium height fences/hedges between gardens. Overall, garden space should be designed to be as green as possible.

Research on health and the built environment is complex and challenging. This study clearly has limitations. By using crosssectional data, causality and possible residential self-selection are impossible to prove. The relatively poor response rate in the survey is a clear weakness of the study; if funding had allowed, an interview-based study would have been more effective. Further, the study would have benefitted from the use of an extensively validated well-being measure - since the study began, a shortened version of Warwick Edinburgh Mental Well-being Scale (Stewart-Brown et al., 2009) has been developed. The findings may also be context specific - that is related to cultural preferences in the UK.

The research paves the way for a prospective longitudinal study, perhaps quasi-experimental in nature through the use of a sample of people moving home. What is of broad international relevance is the study's confirmation of the need to investigate the role of individual, qualitative aspects of the built environment in identifying meaningful relationships with health and well-being. It has also underlined the value of measuring these built environment characteristics objectively. Little progress will be made in creating more healthy 
environments unless research provides evidence on the role of these individual characteristics, because this is what is needed by architects, urban designers, developers and others responsible for shaping the built environment.

This study adds to the growing evidence that the design of the built environment affects people's well-being. There is increasing recognition of the importance of well-being to society, not just in the UK but worldwide; it is a predictor of physical and mental health as well as economic productivity. Architects, urban designers and engineers as well as policymakers in these fields have endless opportunities, through creating, shaping and adapting environments, to make a real difference.

\section{Acknowledgements}

This study was undertaken as part of the I'DGO TOO (Inclusive Design for Getting Outdoors, second phase) research project, supported by the UK Engineering and Physical Sciences Research Council. The I'DGO consortium consists of Edinburgh College of Art, Edinburgh University, Heriot-Watt University, University of Warwick and University of Salford. Further information is available at www.idgo.ac.uk. The authors are grateful to Dr Nicola Dempsey and Amanda Griffin for their help in collecting the data.

\section{REFERENCES}

Beil K and Hanes D (2013) The influence of urban natural and built environments on physiological and psychological measures of stress: a pilot study. International Journal of Environmental Research and Public Health 10(4): 1250-1267, http://dx.doi.org/10.3390/ijerph10041250.

Beukeboom CJ, Langeveld D and Tanja-Dijkstra K (2012) Stress-reducing effects of real and artificial nature in a hospital waiting room. Journal of Alternative and Complementary Medicine 18(4): 329-333, http://dx.doi.org/ 10.1089/acm.2011.0488.

Bond L, Kearns A, Mason P et al. (2012) Exploring the relationships between housing, neighbourhoods, and mental wellbeing for residents of deprived areas. BMC Public Health 12: 48, http://dx.doi.org/10.1186/1471-2458-12-48.

Burton E, Mitchell L and Stride C (2011) Good places for ageing in place: development of objective built environment measures for investigating links with older people's wellbeing. BMC Public Health 11: 839, http://dx.doi.org/ 10.1186/1471-2458-11-839.

Clarke P, Ailshire J, Melendez R, Bader M and Morenoff J (2010) Using Google Earth to conduct a neighbourhood audit: reliability of a virtual audit instrument. Health and Place 16(6): 1224-1229, http://dx.doi.org/10.1016/j.healthplace. 2010.08.007.

de Vries S, Verheij RA, Groenewegen PP and Spreeuwenberg P (2003) Natural environments - healthy environments? An exploratory analysis of the relationship between green space and health. Environment and Planning $A$ 35(10): 1717-1731, http://dx.doi.org/10.1068/a35111.

Duarte CS, Chambers EC, Rundle A and Must A (2010)

Physical characteristics of the environment and BMI of young urban children and their mothers. Health and Place 16(6): 1182-1187, http://dx.doi.org/10.1016/ j.healthplace.2010.07.009.

Dunstan F, Weaver N, Araya R et al. (2005) An observation tool to assist with the assessment of urban residential environments. Journal of Environmental Psychology 25(3): 293-305, http://dx.doi.org/10.1016/j.jenvp.2005.07.004.

Dunton GF, Kaplan J, Wolch J, Jerrett M and Reynolds KD (2009) Physical environment correlates of childhood obesity: a systematic review. International Association for the Study of Obesity 10(4): 393-402, http://dx.doi.org/10.1111/j. 1467-789X.2009.00572.x.

Field A (2009) Discovering Statistics Using SPSS, 3rd edn,. Sage, London, UK.

Gale CR, Dennison EM, Cooper C and Aihie Sayer A (2011) Neighbourhood environment and positive mental health in older people: the Hertfordshire Cohort Study. Health and Place 17(4): 867-874, http://dx.doi.org/10.1016/j. healthplace.2011.05.003.

Galea S, Ahern J, Rudenstine S, Wallace Z and Viahov D (2005) Urban built environment and depression: a multilevel analysis. Journal of Epidemiology and Community Health 59(10): 822-827, http://dx.doi.org/10.1136/jech.2005.033084.

Gilroy R (2008) Places that support human flourishing: lessons from later life. Planning Theory and Practice 9(2): 145-163, http://dx.doi.org/10.1080/14649350802041548.

Gilroy R, Kellet P and Jackson S (2004) Contrasting living arrangements for older people. Paper presented at the ENHR Conference, 2-6 July 2004, Cambridge, UK.

Grahn P and Stigsdotter UK (2010) The relation between perceived sensory dimensions of urban green space and stress restoration. Landscape and Urban Planning 94(3-4): 264-275, http://dx.doi.org/10.1016/j.landurbplan. 2009.10.012.

Howden-Chapman P, Matheson A, Crane J et al. (2007) Effect of insulating existing houses on health inequality: cluster randomised study in the community. British Medical Journal 334: 460. http://dx.doi.org/10.1136/bmj.39070. 573032.80 .

Jackson LE (2003) The relationship of urban design to human health and condition. Landscape and Urban Planning 64(4): 191-200, http://dx.doi.org/10.1016/S0169-2046(02)00230-X.

Kaplan R (2001) The nature of the view from home: psychological benefits. Environment and Behaviour 33(4): 507-542, http://dx.doi.org/10.1177/00139160121973115.

Kuo FE and Sullivan W (2001) Aggression and violence in the inner city: effects of environment via mental fatigue. Environment and Behavior 33(4): 543-571, http://dx.doi.org/ $10.1177 / 00139160121973124$. 


\section{Offprint provided courtesy of www.icevirtuallibrary.com Author copy for personal use, not for distribution}

Li HN, Chau CK, Tse MS and Tang SK (2012) On the study of the effects of sea views, greenery views and personal characteristics on noise annoyance perception at homes. Journal of the Acoustical Society of America 131(3): 2131-2140, http://dx.doi.org/10.1121/1.3681936.

Liu C-W, Everingham J-A, Warburton J, Cuthill M and Bartlett H (2009) What makes a community age-friendly: a review of international literature. Australasian Journal on Ageing 28(3): 116-121, http://dx.doi.org/10.1111/j.1741-6612.2009. 00355.x.

Lottrup L, Grahn P and Stigsdotter UK (2013) Workplace greenery and perceived level of stress: benefits of access to a green outdoor environment at the workplace. Landscape and Urban Planning 110: 5-11, http://dx.doi.org/10.1016/ j.landurbplan.2012.09.002.

Mair C, Diez Roux AV and Galea S (2008) Are neighbourhood characteristics associated with depressive symptoms? A review of evidence. Journal of Epidemiology and Community Health 62(11): 940-946.

Mytton OD, Townsend N, Rutter H and Foster C (2012) Green space and physical activity: an observational study using Health Survey for England data. Health and Place 18(5): 1034-1041, http://dx.doi.org/10.1016/j.healthplace. 2012.06.003.

Northridge ME, Sclar ED and Biswas P (2003) Sorting out the connections between the built environment and health: a conceptual framework for navigating pathways and planning healthy cities. Journal of Urban Health 80(4): 556-568, http://dx.doi.org/10.1093/jurban/jtg064.

Prieto-Flores ME, Fernandez-Mayoralas G, Forjaz MJ, Rojo-Perez F and Martinez-Martin P (2011). Residential satisfaction, sense of belonging and loneliness among older adults living in the community and in care facilities. Health and Place 17(6): 1183-1190, http://dx.doi.org/10.1016/j. healthplace.2011.08.012.

Srinivasan S, O'Fallon L and Dearry A (2003) Creating healthy communities, healthy homes, healthy people: initiating a research agenda on the built environment and public health. American Journal of Public Health 93(9): 1446-1450, http://dx.doi.org/10.2105/AJPH.93.9.1446.

Stewart-Brown S, Tennant A, Tennant R et al. (2009) Internal construct validity of the Warwick-Edinburgh Mental Well-being Scale (WEMWBS): a Rasch analysis using data from the Scottish Health Education Population Survey. Health and Quality of Life Outcomes 7(15): 1-8, http://dx.doi.org/10.1186/1477-7525-7-15.

Tabachnick BG and Fidell LS (2007) Using Multivariate Statistics, 5th Edition. Pearson, Chicago, IL, USA.

Thomson H, Thomas S, Sellstrom E and Petticrew M (2009) The health impacts of housing improvement: a systematic review of intervention studies from 1987 to 2007. American Journal of Public Health 99(S3): S681-S692, http://dx.doi.org/10.2105/AJPH.2008.143909.
Ulrich RS, Simons RF, Losito BD et al. (1991). Stress recovery during exposure to natural and urban environments. Journal of Environmental Psychology 11(3): 201-230, http://dx.doi.org/10.1016/S0272-4944(05)80184-7.

van den Berg AE, Maas J, Verheij RA and Groenewegen PP (2010) Green space as a buffer between stressful life events and health. Social Science \& Medicine 70(8): 1203-1210, http://dx.doi.org/10.1016/j.socscimed.2010.01.002.

Veenhoven R (2010) Greater happiness for the greater number? Journal of Happiness Studies 11(2): 605-629, http://dx.doi.org/10.1007/s10902-010-9204-z.

Velarde MD, Fry G and Tveit M (2007) Health effects of viewing landscapes - landscape types in environmental psychology. Urban Forestry \& Urban Greening 6(4): 199-212, http://dx.doi.org/10.1016/j.ufug.2007.07.001.

Ward Thompson C, Roe JJ, Aspinall P et al. (2012) More green space is linked to less stress in deprived communities: evidence from salivary cortisol patterns. Landscape and Urban Planning 105(3): 221-229, http://dx.doi.org/10.1016/ j.landurbplan.2011.12.015.

White MP, Alcock I, Wheeler BW and Depledge MH (2013) Would you be happier living in a greener urban area? a fixed effects analysis of longitudinal panel data. Psychological Science 24(6): 920-928, http://dx.doi.org/ 10.1177/0956797612464659.

WHO (World Health Organisation), 2007. Global Age-Friendly Cities: A Guide. WHO, Geneva, Switzerland.

Wilson EO (1984) Biophilia. Harvard University Press: Cambridge, MA, USA.

Yen IH, Michael YL and Perdue L (2009) Neighborhood environment in studies of health of older adults. American Journal of Preventive Medicine 37(5): 455-463, http://dx.doi.org/10.1016/j.amepre.2009.06.022.

\section{WHAT DO YOU THINK?}

To discuss this paper, please email up to 500 words to the editor at journals@ice.org.uk. Your contribution will be forwarded to the author(s) for a reply and, if considered appropriate by the editorial panel, will be published as discussion in a future issue of the journal.

Proceedings journals rely entirely on contributions sent in by civil engineering professionals, academics and students. Papers should be 2000-5000 words long (briefing papers should be 1000-2000 words long), with adequate illustrations and references. You can submit your paper online via www.icevirtuallibrary.com/content/journals, where you will also find detailed author guidelines. 